\title{
SOCIAL MEDIA IN SECOND LANGUAGE CLASSROOM: A SURVEY OF ESL STUDENTS AT UNIVERSITY LEVEL
}

\author{
Mubarak Lashary \\ Assistant Professor, University of Sindh Jamshoro \\ mubarak.lashari@usindh.edu.pk \\ Muntazar Mehdi \\ Assistant Professor, National University of Modern Languages, Islamabad \\ mmehdi@numl.edu.pk \\ Yasir Arafat \\ Assistant Professor, National University of Modern Languages, Islamabad \\ yarafat@numl.edu.pk
}

\begin{abstract}
This paper intends to analyze the choice of social media from Facebook, Twitter, WhatsApp, or any other means of communication by the students in learning English at university level. Social media has turned out to be a social reality of today's world, particularly in the field of academics. The use of social media is not restricted to any social sphere of human life irrespective of any social varialbles. All the people are consumers of it in either one or the other way. Through this study, the dominant choice in various perspectives and its uses have been unfolded. The study is quantitative and tries to explore how the ESL students are trying to use social media in learning second language. The sample for the study is non-probability where 50 students from the Institute of English Language and Literature, University of Sindh, Jamshoro, Pakistan have been selected on the non-proportional quota basis. The researchers received 48 questionnaires from the respondents. The questionnaire is mainly close-ended with nominal response category; however, ut some open-ended options were given to get a deeper insight into the issue. The data is analyzed by simple arithmetic and percentage. The conclusion is based on the findings of the data. In order to seek the possibility of the use of social media in the language learning or literary upheaval in using social media, the researchers found out that students are inclined towards the use of social media and it is helpful in the academics and learning the second language in multiple ways.
\end{abstract}

Keywords:Social Media, Facebook, Twitter, WhatsApp, academic purpose, Language learning

\section{INTRODUCTION}

The advent of social media has a significant influence on the way students engage themselves in learning and the model adopted by instructors in teaching or making students learn. Therefore, it has become not only a thing of passing the time or getting entertainment but also a lot more as a penetrating tool in society and its users. It has become an inevitable force for policymakers, users, learners, and other marketing agents to address social media properly before addressing any other issue as a result of its use and compatibility. According to Mariam Webster 'forms of electronic communication (such as websites for social networking and microblogging) through which users create online communities to share information, ideas, personal messages, and other content (such as videos)' ${ }^{1}$. Social media is also defined as mentioned by Boateng and Amankwaa (2016) the application that allows the users to converse and interact with each other to create, edit, and share new forms of textual, visual, and audio content. The advent of social media has influenced significantly how students learn and the way the teachers teach. The advent of social media provides students with a range of academic benefits and opportunities to enhance their learning process (Okoro, 2012). It has transformed the world into a global world. The main purpose of this

\footnotetext{
${ }^{1}$ https://www.merriam-webster.com/dictionary/social\%20media
} 
research is to examine the impact of using social media on academic performance. The new social networks, such as Instagram, Facebook, WhatsApp, Twitter, etc., can have an immediate effect on the behavior and academic performance of the universities and the students (Lau, 2017). It is important to know the facts and figures that are included in these social networks and their benefits to both the teachers and the taught. Finally, the focus will be on the technical side of the social media, which would denote the way it has been linked closely with social media and the way it has changed the mode of teaching and learning, the coordination between the teachers and the students learning, and what content and form are used for what purpose (Kabilan, Ahmad \& Abidin, 2010).

\section{Background to the Study}

The study was undertaken keeping in view the technological awareness, availability and access of the region i.e. Jamshoro a city of Sindh. As compared to the urbanized environment of the city, it is located in a developing area rather it is an underdeveloped locale. The technological gadgets and facilities are not that much available as comparet to the main cities in Pakistan. Hence, a survey of the students in regard to second language learning through social media was indispensable to be conducted in order to view the possibilities of second language learning online or through social media.

\section{Significance of the Study}

The study is significant both for the students and the teachers. The teachers would get to know about the inclinations of the students towards the use of social media as to how much it attracts them towards different modes of social meida. Similarly, it will also helo students get to know how it can help them learn the second language through different social meida sources.

\section{Objectives}

To identify the helpfulness of social media in learning second language

To explore the availability of technological resources in learning the second language

\section{LITERATURE REVIEW}

Social media has turned out to be one of the most immediately and easily accessible mediums of communication in the current scenario. All types of information can be passed on to the masses in just one click and the same can easily be accepted by the receivers individually or in groups. Social media is source to bring together the shared knowledge in learning second language or at higher education level (Desmal, 2017). Every day a lot of pictures and video clips are passed on to the people and at times they do not have enough sources to verify the information being passed on. Almost every individual has the facility to access social media in any form. The term "Social media" may be interpreted as the application which allows its users to interact and communicate among themselves to edit, share and create new ways of audio, video, and textual content; moreover, it categorizes, recommends, and labels existing forms of content (Selwyn 2012). However, Siddiqui and Singh (2016) have posited a question or observation that all videos or friends on social media are not real or culture friendly. Hence, it is mandatory to be very careful of such material whether it is positive or nrgative in the context of education and culture. In addition, social media is accessible to users through the internet by using different devices such as mobile phones, laptops, and desktops. By using such devices, social media connects people to freely and easily communicate. Collaboratively interact, discuss and participate in important issues and exchange views with the available and connected online community (Fewkes\& McCabe2012). Social media has made all this communication easy and less cost-effective too as the costs have gone down many times.

In recent times, technology has developed and has been playing role in the social construction and educational development very significantly and plausibly besides, if it is mishandled, it can destroy nations at the same time as we observe that a lot of data is available and just one click gets one to that data for consumption. Today, it is also a fact that the researchers have also been paving their way to a higher pedestal of research and getting the support of highly qualified persons and scholarships through this social media facility. As asserted by poza-Lojan and 
Calduch-Poza (2017) that teachers try to use such platforms for their self promotion in the educational context besides they try to present material according to their audience's interests and requirements. Simultaneously, Safder, Khan and Abbasi are of the view that social media platforms are not only used for the promotion or privacy scope of teachers but it is, at the same time, conducive for the promotion of education by providing a plat form to the students to get connected with each other. Overall, we may find that the different channels of social media have changed the social, financial, and educational dynamic in the world. In addition, it is also an open secret that these media such as Facebook, Twitter, Google, Google meet, Zoom, etc have brought people together as well as brought many changes in the teaching-learning environment and facilities. Lectures and discussions can be viewed and recorded for later consumption and usage which has made the world a global village.

Nowadays social media is considered a very essential thing in every aspect of life. It is rapidly altering the communication system. With the evolution of social media, the academic life of the students has proportionally evolved or altered. The institutions and the academies have engaged to furnish students' critical thinking skills, enhance their knowledge and information with the help of social media. Selwyn (2012) claims Social Media has influenced the academic life of students. He believes that today the social media is conventionalized in all the higher education institutions that provide the platforms to students where they get in touch with their teachers, classmates, and with all the higher authorities in an attractive manner.

In the last few years technology has played a significant role in helping students of second language a lot. Technology has altered the way of interaction among people. Fewkes and McCabe(2012) and Fischer (2013) have come up with the point that the use of technology in higher education has also altered ways of communication and cooperation among instructors, students, and others on the tasks of knowledge construction in learning. According to Kessler (2013), there is an emerging pedagocical potential through the optimal use of modern day technologies besides these emerging pedagogy can enhance the teaching of second/foreign language. Similarly, Mansor and Rahim (2017) recommended that by applying the social media sites in the ESL classroom, not only will the students be proficient in learning language but it will also develop socialization among them. Also mansor (2016) is of the view that learning language on social media has also demanded good communication skills which is very important in any education system during Information Communication System (ICT). Anankulladetch (2017) also proclaimed that students can exchange multiple thoughts besides they can learn language skills on social media. There are different strategies for learning vocabulary, grammar, literature, science subjects, etc. With the increasing time, scope, and frequency of use of the internet the number of students using the internet has also increased (Khan, Dickinson \& Kubler, 2013).

Social media provides the students with a new mechanism for a familiar exercise. It provides students with a direct medium by which they can learn in the most effective way than they did in the past through contact with their teachers and learned by all means (Dunn, 2013). Students also use social media for group study. In general, students use social media as a platform for discussion on their assignments and other coursework. It provides students a direct medium by which to publicly evaluate and comment on their campus environments, institutional policies, classes, professors, administration, and fellow students in real-time; in short, it has become a discussion forum (Margerison, 2013). Social media in education is used to foster collaboration and cooperation by allowing for social interactions, and various curricular or non-curricular activities of the students.

An understanding of social media, its use, and how it is influencing students learning environment would be of great relevance to students, researchers, students' affairs, practitioners, and all the various bodies that come to play when talking of social media and school life. The outcome of the study will help to strategize and reconstruct their attitude regarding the use of social media. It will also push people further to identify the exciting opportunities that social media adds to human and student life as a whole (Humphreys, 2013). Academic life in these contexts is described as the activities which relate to the work done in colleges and universities especially those that involve studying and reasoning rather than practical or technical skills. Higher education on the other hand is an educational level that primarily describes post-18 learning that takes place at 
the universities as well as other colleges and institutions which award academic degrees and professional qualifications. Chug and Ruhi (2018) have also stated that rapid adoption of social media in higher education has brought a fundamental shift in learning. Not only the students and teachers but also the staff have started using social media which has brought a great change in their lives. Hence, it is important to explore how these technologies can be used for academic purposes of higher education (p. 605) A side most deliberations of social media being perceived as either on the very straightforward or the very philosophical, emergent numbers of educationalists exploring and aspiring in this field are beginning to consider the possible significance and likely implications of social media for education practice and provisioned especially in terms of higher education. Social media constitutes an increasingly important context in one's academic everyday life. Indeed, some critics talk of social media as a self-networked acknowledging avenue serving as a key site for sociality and identity recognition in many people's lives (Papacharissi, 2010).

\section{METHODOLOGY}

The study is quantitative and tries to explore the technological facilities for learning the second language. University if Sindh Jamshoro was the site for the case study of the exploration of scope of the second language learning. Non-probability sample was used from the ESL undergraduate and graduate students of the university. A total of 50 respondents -25 male and 25 female students were selected keeping in view the non-proportional quota sample for the study. A questionnaire was framed in order to actuate the objectives of the study. The questionnaire was closed-ended and nominal response format was used. In certain case, the students were given open-ended options to get deeper insight in to the study.

\section{Data Collection}

The data for the study were collected from 5 classes of IELL including the students of the later stage of BS hons degree i.e. from $5^{\text {th }}$ to $8^{\text {th }}$ semesters in linguistics and literature and the students of M.Phil linguistics and literature. Overall fifty students were selected based on their willingness to participate in the study who were given questionnaires having an equal share of 25 male and 25 female students, out of the 48 questionnaires were returned with an equal number of 24 males and 24 female students. All the students were informed before handing over the questionnaire regarding choice(s) of selection as they could choose more than one option and they could include anything that was not mentioned in the options to make the questionnaire all-inclusive inquiry so that the participants may feel easy to express. The questionnaire consisted of 15 questions/statements with varying options to select and almost all the statements included one open space to write if something more than the options is necessary to include.

\section{DISCUSSION AND ANALYSIS}

Simple Arithmetic and descriptive approach are used to analyze the data collected in the questionnaire (see appendix 1). First, of all the responses of all the participants regarding their choice of social media, the purpose of using social media and other such inquiries were analyzed and a percentage was drawn. Secondly, the comparison between the female and male students' choices and their simple ratio ware was drawn or calculated. This Arithmetic and descriptive approaches demonstrate the application of mixed methods i.e. quantitative and qualitative methods for the results and conclusion. The general calculation of the study can be seen below with general choices of the options of the questionnaire by both genders;

The first question of the questionnaire was regarding the demographic information on gender i.e.male, female, other, and prefer not to say. In response to that question, the participants clearly showed their gender either male or female without any options that stood as 24,24 females, and males respectively.

In this regard, the data coming up after analysis was given in tables in general, whereas, its variation regarding gender-wise analysis was discussed descriptively. The questions/statements were given as the title of the table for rapid understanding. The first question of the questionnaire was about gender that simply stood 24, 24 respectively as mentioned above, whereas, data here starts with question no.2. The data and analysis is given below: 


\section{What social media platform do you use the most?}

1. Facebook 2. Twitter 3. WhatsApp 4. YouTube

In the options, the use of WhatsApp is more dominant as nine participants selected more than one option in which 8 participants have $3^{\text {rd }}$ option i.e. WhatsApp that becomes total of 26 whereas second most was facebook as $1^{\text {st }}$ option that becomes 25 . Finally, two more options were mentioned in others which are Instagram and google, perhaps, google plus or google drive, etc. In the conclusion, it can be said that the usage of WhatsApp and Facebook is more common than any other sources of social media in this context.

\section{How much time do you spend on social media?}
1. 1-2 hours
2. 2-3 hours
3. 3-4 hours
4. More than 4 hours
Other (please specify)

The above data shows that the participants use social media mostly for 1-2 hours daily. The ratio stands at $39 \%$ of the students. Surprisingly, the second most selected option was $4^{\text {th }}$ which describes that $29 \%$ of students use social media more than 4 hours a day. The remaining two options i.e. second and third options are in between. It shows that either they use 1-2 hours or they use more than 4 hours means either the lowest or highest time-consuming activity takes place.

\section{What type of content do you like to see on social media?}

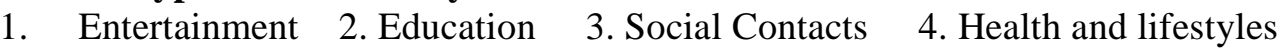

Other (please specify)

In response to 'what type of content do they like to see on social media?' shows that educational content is dominantly seen by the participants, that is 21 having $43 \%$ solely. The second more used contents are equally entertaining and social contacts with 8 responses having $16 \%$ respectively, whereas, two participants included technical/technological contents and news as well. In more than one option 10 respondents included in which entertainment was selected by 4 participants, educational content was selected by 9 respondents and option 3 was selected by 7 respondents. Again, overall educational content remained the first choice of the majority and the second majority option was social contacts.

\section{How do you prefer to see it?}

\section{Article blogs 2. Videos \\ 3. Pictures 4. Ads}

Other (please specify)

In responses to question 5, the majority in the only selection option remained 'article blogs' up to $31 \%$ and second higher is videos but those who selected more than one option 12 in numbers are having videos in the majority. It shows that our learners are more inclined to moving stuff where 9 respondents selected option 2 . On the other hand 7 respondents on more than one respondent selected 'article blogs' 7 times. The final ratio stands equal.

\section{At what times are you most active on social media?}

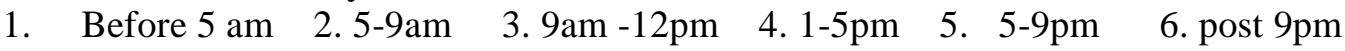

In responses to question no 6 , it is very clearly seen that a huge majority of participants use social media after $5 \mathrm{pm}$ on onward even more than that is post $9 \mathrm{pm}$ which is 39 percent of the numbers. In that options just more than 2 participants marked two options in both option 3 is included it means majority use social media after $5 \mathrm{pm}$ and they may be continuing till post $9 \mathrm{pm}$ as well.

\section{On social media, are you more interested in:}

\section{Products 2. Services 3. Advice 4. General chat 5. promotions and offers}

Other (please specify)

In response to 'They are interested in social media?', the majority went for promotions and offers. This option was deliberately kept aside from education to know that what sort of other things are more keenly seen. As the table and data show that they were interested in promotions and offers as the most and secondly they use it for general chat whereas, services, products are of less importance 
for them. Four options were written were 2 participants told that they see things if they are related to education and one told that $\mathrm{s} / \mathrm{he}$ is interested in news and current issues as well.

\section{For group study/ preparation we use:}
1. Facebook
2. WhatsApp
3. Twitter
4. Emailing

Other (please specify)

In response to a query regarding what they use for group study or some kind of preparation for exams or tests etc., the overwhelming majority showed that they use WhatsApp at $75 \%$ that's a very clear dimension of usage of a single channel. Facebook, which is very dominantly used by the students as can be seen in 2 and other questions which showed that FB is heavily used but for preparation or group study WhatsApp is very much used. Just 2 students mentioned that they use some other sources like face-to-face study.

\section{How often do you use social media for your education and learning?}

\section{Always 2. Sometimes 3. Rarely 4. Not at all}

Other (please specify)

The majority of the participants use social media mainly for educational purposes as it can be seen more than 50 percent of participants responded that they always use it for educational purposes, whereas, 43 percent sometimes use it for education. Remaining all the options are so few, thus, not making any difference in the use of social media without educational purposes. It can be seen as a good gesture.

\section{Social media is more helpful in:}

1. Interaction with class fellows 2 . Learning a new idea 3. Passing the time 4. Knowing about course

Other (please specify)

As the contemporary age is related to innovations and discoveries in ideas, the participants also responded overwhelmingly that the media is more helpful in learning new ideas that stand more than 50 percent solely. The second-highest ratio is interaction with the class fellows. Knowing about courses is always occupying a good percentage because nowadays all the courses or subjects are mainly uploaded on social media i.e. FB pages, WhatsApp groups or given instructions regarding courses to the students by social media. The least frequency in this regard is passing the time that is also a positive sign from students.

\section{Use of social media in an educational institute is:}

\section{$\begin{array}{lll}\text { 1. Motivational 2. Entertaining 3. Disturbance } 4 \text {. Waste of time } & \end{array}$}

Other (please specify)

When it was asked that social media in institutions is positive or negative, the responses were positive. A good majority of more than 60 percent of students believed that the use of social media is motivational and encouraging. The second higher response in this regard was the disturbance and the waste of time 16 and 10 percent respectively. If both of them would be combined still motivational options stand too high. Whereas, a smaller number of students believed that social media in institutes is a source of entertainment.

\section{I use ....for contacting my teachers:}
1. Facebook 2. WhatsApp
3. Twitter
4. Instagram

Other (please specify)

After the first 11 questions/statements related to the dominant type of social media and its choice of content or purpose in general in the following queries, it was focused that how and why individuals use social media. Consequently, in 12 queries it was asked that by what specific social media they contact their teachers. It was very clearly and dominantly shown that the students' contact with their teachers by FB that stands more than 70 percent. Whereas WhatsApp, other sources like SMS or call or personal meeting are making smaller portion up to 3 percent respectively. However, certain 
students from both male and female genders never contact their teachers by any social media, but face to face.

\section{I use......for contacting my class fellows/ students:}
1. Facebook
2. WhatsApp
3. Twitter
4. Instagram

Other (please specify)

Among the responses to this statement, the highest response was that about $54 \%$ of participants use WhatsApp to contact the class fellows or other students. That makes about 14 participants of both male and female participants. The second highest response was that FB is used to make a contact with class fellows whereas seven participants also claimed that other means are also used to contact with class fellows. However, Twitter and Instagram were hardly used by these participants for the above-mentioned purpose.

\section{Students use social media during lecture/class:}
1. Always
2. Sometimes
3. Rarely
4. I don't know
Other (please specify)

The responses to this statement are a bit shocking in this regard that about $42 \%$ of participants claimed that they are not fully aware of this whether students use social media during the class/ lecture. The second-highest number of participants chose the option of 'sometimes they use social media while the class is being conducted or the lecture goes on.

\section{I use social media during lectures/class:}

\section{$\begin{array}{lll}\text { 1. Always 2. Sometimes 3. Rarely } \quad 4 \text {. Not at all } & \end{array}$}

Other (please specify

The participants chose the $3^{\text {rd }}$ option of this statement the most. That is they rarely use social media in the class while the lecture is going on. The second highest response was, surprisingly, that they do not use social media in the class at all while the lecture/class is being conducted.

\section{FINDINGS}

From the above investigation, it can be supposed that social media has transformed the way of student life in not only personal affairs but in communication with teachers, classmates, subject regulations, other students outside the class, and seniors. They use it for various purposes and means. Social media can be divided into various applications used for various purposes. Some applications such as Whatsapp and Facebook are used more as compared to others such as Instagram or Flickr. It depends either on the programs or functions for which these applications of social media are produced and finally used. However, the above responses prove that social media has been quite influential in bridging up the old and stereotypic relationship between teachers and the taught. It has not only modified or transformed the ways of learning things but has also transformed the ways we use them to be in contact within the domain of academics. Whatsapp is the most used application of social media for various purposes. One of the major purposes that students use this application is to communicate with the class fellows for group study or sharing the material. They also use Whatsapp to communicate with teachers, instructors, or other authorities' experts in their area of interest. Whatsapp is quite convenient to share the material, videos, audios, photos, files, and notes within the group or with other students and teachers. Possibly, it is because that this application is widely liked and used by the students. One more thing can be said that it is faster in use and sending some material perhaps it is used.

On the other hand, FB serves to provide the blogs, pages, groups, and other sharing of videos and pictures for both entertainment and academic purposes. Facebook helps students search for the person easily whereas for Whatsapp one has to save the mobile number to contact with. FB provides a wider opportunity for students to get access to tutorial videos and blogs easily.

Gender-wise analysis shows that there is not a big difference in the use of social media in the academic institute. However, some areas are somehow different in choice and selection of medium and usage. For instance, male students usually contact teachers on Whatsapp whereas female students do it on Facebook. Similarly, data shows that some female students useless 
facebook than male students and their purposes for them are somehow different. Interestingly, one female student replied that to query no 11 that social media is waste of time whereas she in other responses told that she is using FB, Whatsaap, Instagram, and other channels of media. More interestingly, the same student's ratio of usage of the media is higher than many students.

\section{CONCLUSION}

It can be concluded from the study that social media as part of technical development is highly used in academics for different purposes. Social media as being a current social reality in the contemporary world is not unknown or unrecognized for educational setup and its stakeholders. Students being a large sum of the institutional population are very much keen to use modern technology. This study shows that the students of IELL, University of Sindh, Jamshoro, are also not lagging in the advanced technological world where education goes with its development. From the findings, we could ascertain that Whatsapp and Facebook are the channel of social media that are dominantly used by the students for varying purposes. These channels of social media are not only used for entertainment and passing the time but more than that these are used for educational purposes. It can also be seen that when these modes are inevitable in academics, therefore, how could they be utilized for positive purposes and more productive academic use? This kind of study can be the source of understanding the potential of social media and its usage for beneficial outcomes in some ways. Therefore, the policyholders may seriously think of this kind of thing properly in the light of findings and data analysis.

\section{REFERENCES}

Boateng, R., \& Amankwaa, A. (2016). The impact of social media on student academic life in higher education. Global Journal of Human-Social Science, 16(4), 1-8.

Chugh, R., \& Ruhi, U. (2018). Social media in higher education: A literature review of Facebook. Education and Information Technologies, 23(2), 605-616.

Cifuentes, O. E., \& Lents, N. H. (2011).Increasing student-teacher interactions at an urban commuter campus through instant messaging and online office hours. Electronic Journal of Science Education, 14, 1-13

Desmal, A. J. (2017). The impact of using social media and internet on academic performance case study Bahrain Universities. EAI Endorsed Transactions on Scalable Information Systems, $4(13)$.

Doering, A., Lewis, C., Veletsianos, G., \& Nichols-Besel, K. (2008).Preservice teachers' perceptions of instant messaging in two educational contexts.Journal of Computing in Teacher Education, 25, 5-12.

Fewkes, A. M. \&McCab, M. (2012). Facebook: Learning Tool or Distraction? Journal of Digital Learning in Teacher Education | Volume 28 Number 3

Humphreys, L. (2013). Mobile social media: Future challenges and opportunities. Mobile Media \& Communication, 1(1), 20-25.

Kabilan, M. K., Ahmad, N., \& Abidin, M. J. Z. (2010). Facebook: An online environment for learning of English in institutions of higher education?. The Internet and higher education, 13(4), 179-187.

Lau, W. W. (2017). Effects of social media usage and social media multitasking on the academic performance of university students. Computers in human behavior, 68, 286-291.

Mansor, N. (2016). Enhancing communication via social media in ESL classroom. In 6th International Conference on Language, Education, and Innovation (Vol. 52, pp. 140-146).

Mansor, N., \& Rahim, N. A. (2017). Instagram in ESL classroom. Man in India, 97(20), 107-114.

Margerison, J. (2013). Online discussion forums in the classroom: Can the principles of social media benefit literacy and enhance engagement with learning?. Literacy Learning: The Middle Years, 21(2), 19-28.

Okoro, E. (2012). Integrating social media technologies in higher education: Costs-benefits analysis. Journal of International Education Research (JIER), 8(3), 255-262.

Papacharissi, Z. (Ed.). (2010). A networked self: Identity, community, and culture on social network sites. Routledge. 
Poza-Lujan, J. L., \& Calduch-Losa, Á. (2017). Social Media as a Tool, and Tools Offered by Social Media, to Teachers and Researchers: Personal or Professional Use?. In Digital Tools for Academic Branding and Self-Promotion (pp. 66-80). IGI Global.

Rambe, P., \&Chipunza, C. (2013).Using mobile devices to leverage student access to collaboratively-generated resources: A case of WhatsApp instant messaging at a South African University.In International Conference on Advanced Information and Communication Technology for Education. Amsterdam: Atlantis Press

Selwyn, N. (2012). Social media in higher education. The Europa world of learning. London: Routledge

Siddiqui, S., \& Singh, T. (2016). Social media its impact with positive and negative aspects. International journal of computer applications technology and research, 5(2), 71-75.

Smit, I. (2012). WhatsApp with BlackBerry; can messengers (BBM) be MXit? In Proceedings of the 14th Annual Conference on World Wide Web Applications. Cape Town: Cape Peninsula University of Technology.

Sweeny, S. M. (2010). Writing for the instant messaging and text messaging generation: Using new literacies to support writing instruction. Journal of Adolescent \& Adult Literacy, 54, $121-$ 130. http://dx.doi.org/10.1598/JAAL.54.2.4

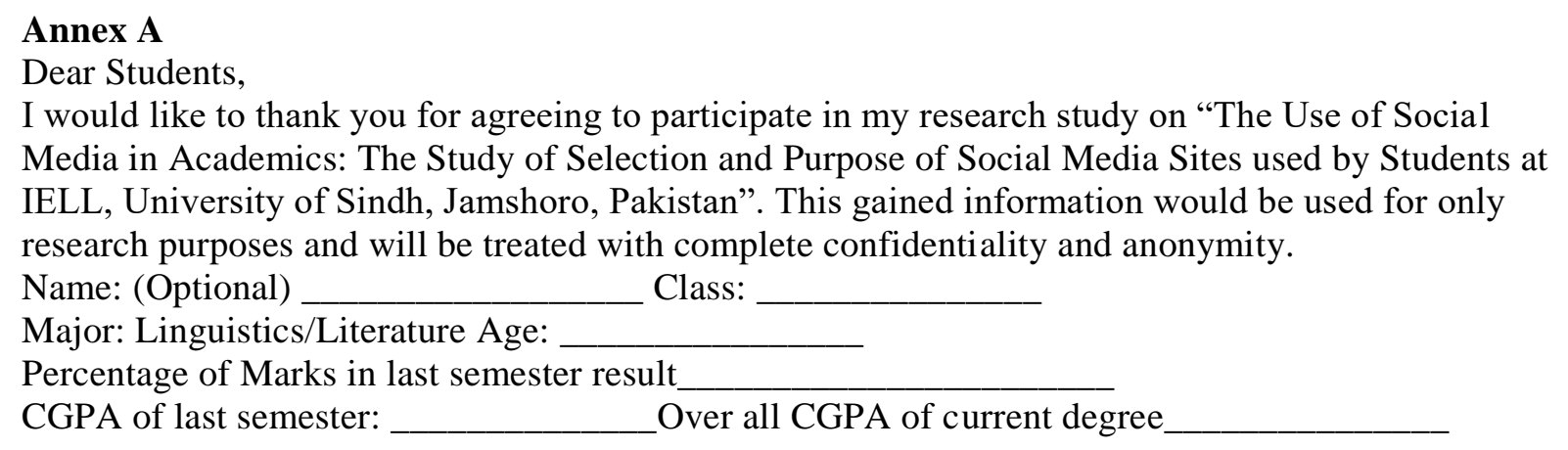

1. What is your gender?

1. Female 2. Male 3. Other 4. Prefer not to say

2. What social media platform do you use the most?

1. Facebook 2. Twitter 3. WhatsApp 4. YouTube

Other (please specify)

3. How much time do you spend on social media?

2. 1-2 hours 2. 2-3 hours 3.3-4 hours 4. More than 4 hours

4. What type of content do you like to see on social media?

2. Entertainment 2. Education 3. Social Contacts 4. Health and lifestyles

Other (please specify)

5. How do you prefer to see it?

2. Article blogs 2. Videos 3. Pictures 4. Ads

Other (please specify)

6 . At what times are you most active on social media?

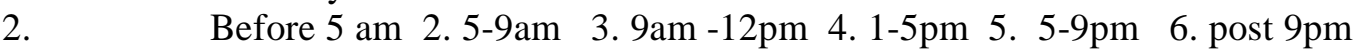

7. On social media, are you more interested in:

1. Products 2. Services 3. Advice 4. General chat 5. promotions and offers

Other (please specify)

8. For group study/ preparation we use:

1. Facebook 2. Whatsapp 3. Twitter 4. Emailing

Other (please specify)

9. How often do you use social media for your education and learning?

1. Always 2. Sometimes 3. Rarely 4. Not at all 
Other (please specify)

10. Social media is more helpful in:

1. Interaction with class fellows 2. Learning a new idea 3. Passing the time 4. Knowing about course

Other (please specify)

11. Use of social media in an educational institute is:

1. Motivational 2. Entertaining 3. Disturbance 4. Waste of time

Other (please specify)

12. I use ....for contacting my teachers:

1. Facebook 2. Whatsapp 3. Twitter 4. Instagram

Other (please specify)

13. I use......for contacting my class fellows/ students:

1. Facebook 2. Whatsapp 3. Twitter 4. Instagram

Other (please specify)

14. Students use social media during lecture/class:

1. Always 2. Sometimes 3. Rarely 4. I don't know

Other (please specify)

15. I use social media during lectures/class:

1. Always 2. Sometimes 3. Rarely 4. Not at all

Other (please specify 